\title{
Development and characterization of nanocomposite materials
}

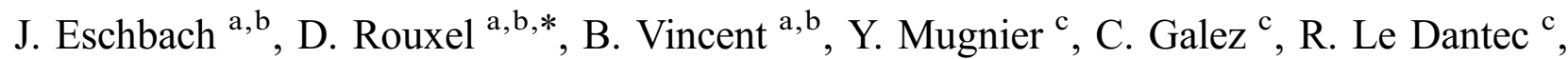 \\ P. Bourson ${ }^{\text {d }, ~ J . K . ~ K r u ̈ g e r ~}{ }^{b, e}$, O. Elmazria ${ }^{\text {a,b }}$, P. Alnot ${ }^{a, b}$ \\ a Laboratoire de Physique des Milieux Ionisés et Applications, CNRS-UMR 7040, Université H. Poincaré, Nancy I, F-54506, France \\ ${ }^{\mathrm{b}}$ Laboratoire Européen de Recherche Universitaire, Saarland-Lorraine, Germany \\ ${ }^{\mathrm{c}}$ Laboratoire Systèmes et Matériaux pour la Mécatronique, Polytech'Savoie, Annecy, France \\ ${ }^{\mathrm{d}}$ Laboratoire Matériaux Optiques, Photoniques et Systèmes, CNRS-UMR 7132, Université Paul Verlaine, Metz, France \\ ${ }^{\mathrm{e}}$ Fachrichtung 7.2, Experimentalphysik, Universität des Saarlandes, Bau 38, D-66041 Saarbrücken, Germany
}

In this paper we present the fabrication and characterization of nanocomposite materials based on crystalline nanoparticles dispersed in an oligomer matrix (DGEBA, used in epoxy resin). Two types of nanoparticles are used. $\mathrm{Al}_{2} \mathrm{O}_{3}$ nanoparticles, commercially available, allow us to carry out the fabrication process of the nanocomposites. This system (DGEBA $+\mathrm{Al}_{2} \mathrm{O}_{3}$ ) is considered as a reference for the second one based on iron iodate nanoparticles fabricated by co-precipitation. The nanocomposite fabrication process is described. The dispersion step and the problems inherent to clusters destruction are underlined. Iron iodate nanoparticles are characterized by TEM, SEM, X-ray diffraction, Raman spectroscopy and EDX. Results point out that the nanoparticles have dimensions between 20 and $30 \mathrm{~nm}$ and present two different morphologies (ball and needle).

Mechanical properties of the nanocomposite based on $\mathrm{Al}_{2} \mathrm{O}_{3}$ are explored by Brillouin spectroscopy. An enhancement of the Young's modulus is observed with a very weak mass percentage of nanoparticles (3\%), the glass transition is also shifted from $247 \mathrm{~K}$ to $251 \mathrm{~K}$. X-ray diffraction measurement on iron iodate nanocomposite demonstrates that nanoparticles remain in the same phase $\left(\mathrm{P}_{3}\right)$ after the nanocomposite preparation process. This result is of great importance in order to achieve piezoelectric and ferroelectric applications.

\section{Introduction}

Due to their various properties, bulk polar dielectric materials as well as thin films find many applications in the fields of sensors, transducers and optical communications. The evolution of these properties at the nanometer scale is also of academic interest. However, the lack of publications in this field attests to the difficulty of growing polar nanocrystals.

In addition, the synthesis of iodate compounds of metal or rare earth ions has known a strong renewed interest in the past 5 years. The specific properties that justify these current works are

\footnotetext{
* Corresponding author. Laboratoire de Physique des Milieux Ionisés et Applications, CNRS-UMR 7040, Université H. Poincaré, Nancy I, F-54506, France.

E-mail address: didier.rouxel@lpmi.uhp-nancy.fr (D. Rouxel).
}

the piezoelectric, ferroelectric, and non-linear optical properties [1-12].

Composite materials are of growing interest and offer a large range of applications in fields as various as mechanics, electronics or optics. Thanks to the exceptional increase of the interface area between the two materials (nanoparticles and matrix), nanocomposites allow in particular to obtain original combinations of mechanical properties. The objective of our work is to combine piezoelectric nanoparticles with polymer matrix. Indeed, many potential applications can be obtained by this combination. First of all, the obtained polymer can be easily put in thin film by spin coating in order to produce low cost devices. These thin films allow easier integration with other electronics or even optics devices like for instance optical waveguide for acouto-optic interactions.

In this paper we present the piezoelectric nanoparticles that we have chosen to integrate in our nanocomposite. The $\mathrm{Fe}\left(\mathrm{IO}_{3}\right)_{3}$ 
nanoparticles are prepared by co-precipitation. Particles are characterized by different techniques, including Scanning Electron Microscopy, Micro-Raman spectroscopy, X-ray diffraction and Transmission Electron Microscopy. In a second time we will present the technique used to disperse the nanoparticles in the polymer matrix. The difficulties inherent to the dispersion process, more precisely to the nanoparticles clusters destruction, will be underlined. In order to define the experimental parameters for the dispersion step we have chosen to use commercially available nanoparticles of $\mathrm{Al}_{2} \mathrm{O}_{3}$. These nanoparticles have allowed us to produce our first nanocomposite and to measure the influence on mechanical properties of the polymer matrix. This study has been achieved by Brillouin spectroscopy. Finally a nanocomposite with piezoelectric nanoparticles have been elaborated. Some difficulties have to be overcome to obtain transparent nanocomposite and to characterize it by Brillouin spectroscopy.

\section{Nanoparticles}

\section{1. $\mathrm{Al}_{2} \mathrm{O}_{3}$ nanoparticles}

As said previously we have used two different nanoparticle types. Alumina nanoparticles commercially available from SIGMA Aldrich allowed us to define a dispersion process. These alumina nanoparticles have an average size of $2-4 \mathrm{~nm}$ and a specific area of $350-720 \mathrm{~m}^{2} / \mathrm{g}$.

\subsection{Fabrication and characterization of $\mathrm{Fe}\left(\mathrm{IO}_{3}\right)_{3}$ nanoparticles}

$\mathrm{Fe}\left(\mathrm{IO}_{3}\right)_{3}$ nanoparticles were synthesised by a co-precipitation method, which allows to obtain a nanometric powder of inorganic polar crystals. Co-precipitation in aqueous solution is a promising way in order to elaborate nanomaterials with specific properties. In addition to the low cost aspect of this method, recent studies show that the size of nanocrystals is an adjustable parameter, which depends on the $\mathrm{pH}$, the ionic force and the temperature $[13,14]$.

$\mathrm{Fe}\left(\mathrm{IO}_{3}\right)_{3}$ powder has been prepared by co-precipitation of iron nitrate $\left(\mathrm{Fe}\left(\mathrm{NO}_{3}\right)_{3} \cdot 9 \mathrm{H}_{2} \mathrm{O}\right.$, Aldrich, 98\%) with iodic acid $\left(\mathrm{HIO}_{3}\right.$, Aldrich, 99.5\%) in aqueous solution. The method is similar to that described by Von Endrédy [15]. First, the reactants are separately dissolved in distilled water and both solutions are stirred for $2 \mathrm{~h}$ at room temperature (RT). Then, the iron nitrate solution is progressively poured into the iodic acid solution while vigorous stirring is maintained. After being heated at $80{ }^{\circ} \mathrm{C}$ for 2 days, the suspension is filtered $(30 \mu \mathrm{m})$ and washed 3 times with distilled water. The obtained powder, which is yellow-green, is dried in airflow at room temperature.

X-ray data were collected at room temperature on a Philips PW1050 powder goniometer with Bragg-Brentano geometry $\left(\mathrm{Cu} \mathrm{K}{ }_{\alpha}\right)$ (Fig. 1a). With our current procedure, the size of the Fe $\left(\mathrm{IO}_{3}\right)_{3}$ nanocrystals is estimated at approximately $20 \mathrm{~nm}$ by X-ray diffraction. This experimental result has been obtained by assuming a lorentzian profile for the diffraction peaks and after correction of instrumental broadening. We have checked the origin of the widening of each diffraction peak by plotting the value $B \cos (\theta)$ ( $B$ is the FWHM for each peak) versus the diffraction angle (Fig. 1B). In the corresponding Williamson plot the constant values of $B \cos (\theta)$ indicate that the broadening of the peaks is due to the size of the nanocrystals and not to stress. The structure refinements show that iron iodate crystallises within the noncentrosymmetric space group $\mathrm{P}_{3}$ [16]. Fig. 1 shows the observed $\mathrm{X}$-ray powder diffraction together with those calculated from the single crystal data for comparison. The observed and calculated $\mathrm{X}$-ray diffraction patterns are in good agreement, which confirms the single phase structure (Fig. 1A).

The morphology of the nanocrystals was determined by SEM and TEM analysis. Two kinds of morphology have been observed: needles with diameter of a few tens of nanometers and length from 20 to several hundred nanometers (Figs. 2 and 3), and round particles of $20-30 \mathrm{~nm}$ in diameter. The average size of approximately $20 \mathrm{~nm}$, in remarkable agreement with the X-ray diffraction analysis, was also confirmed by Atomic Force Microscopy measurements in the Intermittent-Contact mode (IC-AFM, Fig. 4) with an Autoprobe CP research instrument (Veeco). AFM images were obtained after drying and filtering a drop of solution at $110^{\circ} \mathrm{C}$ on a pyrolitic graphite substrate (HOPG). The filtering at $0.22 \mu \mathrm{m}$ removes the clusters of needle-type nanoparticles. One notes a homogeneous spatial distribution of nanocrystals and a narrow size distribution. The measured height is coherent with the
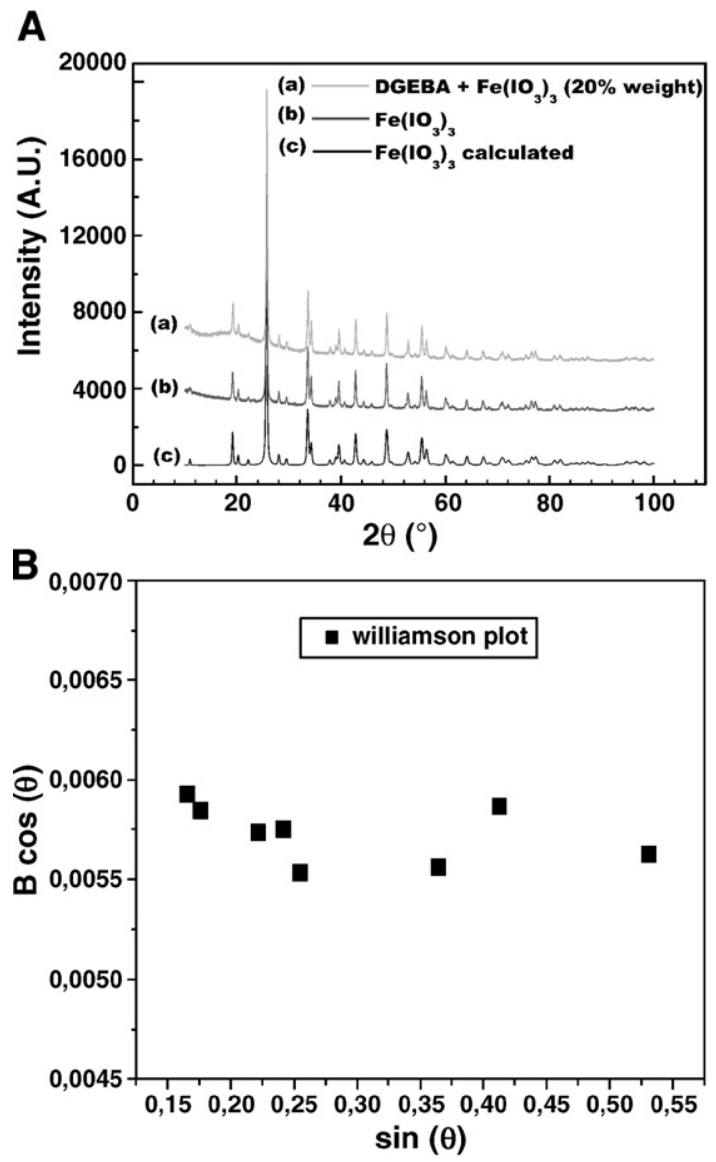

Fig. 1. A: X-ray diffraction patterns of $\mathrm{Fe}\left(\mathrm{IO}_{3}\right)_{3}$. (a) Embedded in a DGEBA matrix, (b) observed on nanopowders and (c) calculated from the single crystal data. B: Williamson plot corresponding to the XRD pattern of $\mathrm{Fe}\left(\mathrm{IO}_{3}\right)_{3}$ nanopowders. 


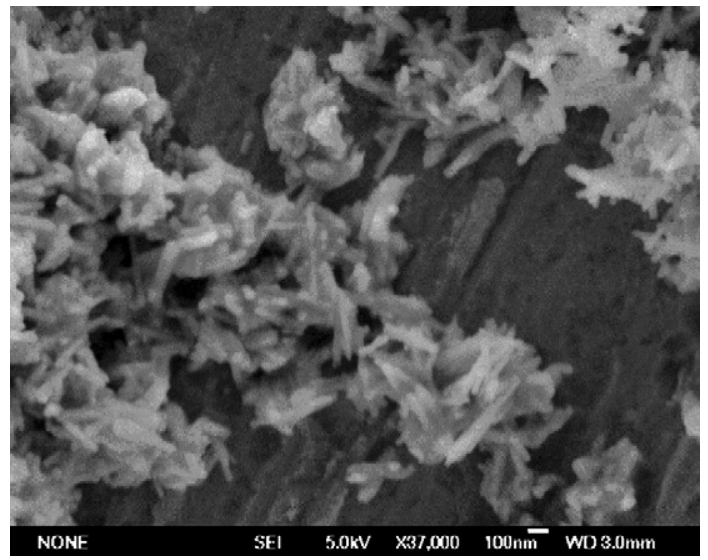

Fig. 2. SEM image of $\mathrm{Fe}\left(\mathrm{IO}_{3}\right)_{3}$ nanocrystals before dispersion.

average size estimated by X-ray diffraction. In addition, some composition analysis has been performed by EDX, showing a homogeneous composition and a good stoichiometry of the nanopowder.

\section{Nanocomposites}

\subsection{Preparation}

We chose a model-like system matrix of the epoxy type: the DGEBA resin (bisphenol A) diglycidylether+the DETA hardener (diethylene triamine). In the case of such a reactive system the elastic properties can be dominated by the existence of the interphases formed in particular around the nanoparticles during the polymerization process.

First of all we have to disperse the nanoparticles inside the oligomer. This is done by using a dispersing system. The main step consists in destroying the clusters formed by the nanoparticles (see Fig. 2). The system used to disperse and crush the clusters is a DISPERMAT ${ }^{\circledR}$ TU. It is composed of a disc which

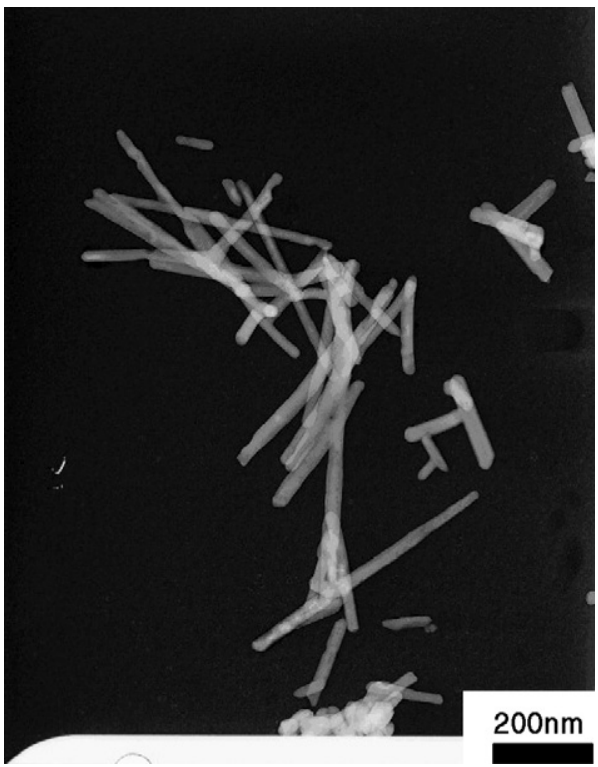

Fig. 3. TEM image of $\mathrm{Fe}\left(\mathrm{IO}_{3}\right)_{3}$ nanocrystals.

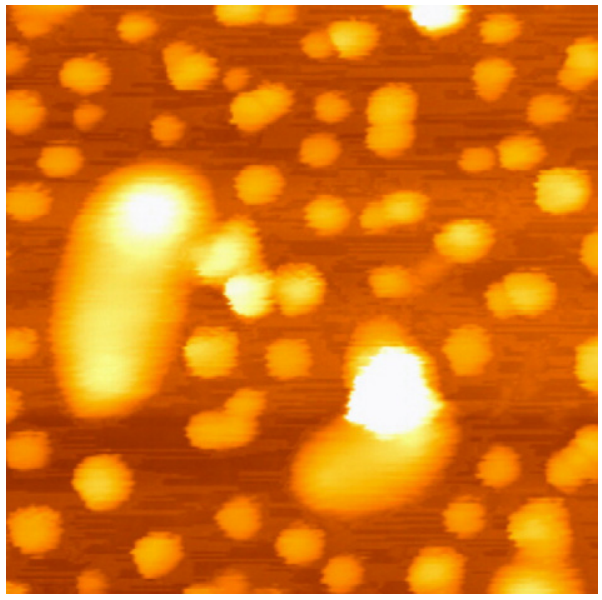

Fig. 4. IC-AFM image of $\mathrm{Fe}\left(\mathrm{IO}_{3}\right)_{3}$ nanocrystals dispersed on $\mathrm{HOPG}\left(1 * 1 \mu \mathrm{m}^{2}\right.$, grey scale $100 \mathrm{~nm})$.

turns up to 20000 rounds per minute. In order to obtain a homogeneous mixture the disc introduces some shearing forces. After the dispersion step the clusters must be removed from the mixture. This is done with another tool by ball milling. The mill consists of ceramic balls $\left(\mathrm{ZrO}_{2}\right)$ added in the mixture, carried around by a planetary disc in rotation up to 6000 rounds per minute. The balls, mixed with the DGEBA and the nanoparticles, crush the clusters.

\subsection{Nanoparticles properties in the composite}

The crystallographic structure of the nanoparticles in the nanocomposite was analysed after the dispersion process. The point was to check that the milling step in particular did not damage the particles, and that the new chemical surrounding medium did not induce a phase change. Fig. 1A compares in particular the X-ray spectrum of the $\mathrm{Fe}\left(\mathrm{IO}_{3}\right)_{3}$ nanocrystals, in powder form, with that of the nanocomposite (DGEBA with $20 \%$ in weight of $\mathrm{Fe}\left(\mathrm{IO}_{3}\right)_{3}$ ). We can see that the spectra are quite similar, excepted for the background related to the amorphous matrix. For the $\mathrm{Fe}\left(\mathrm{IO}_{3}\right)_{3}$

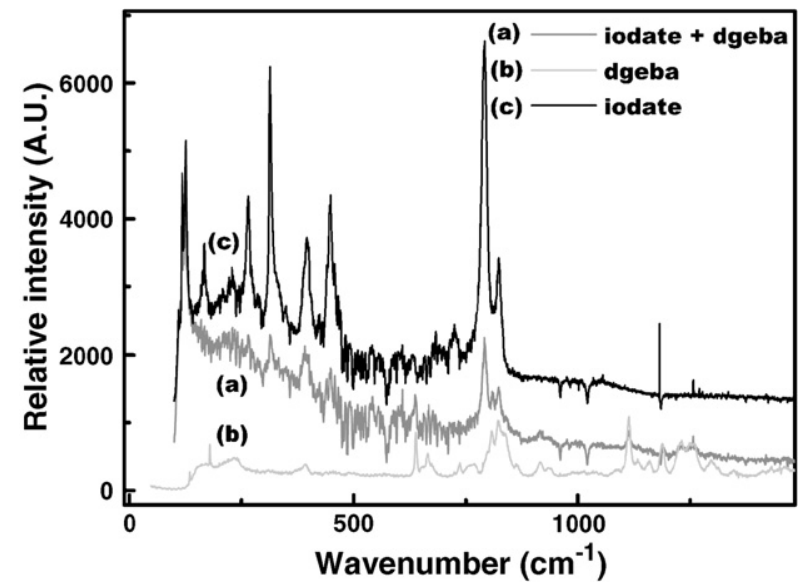

Fig. 5. Raman spectrum of nanocomposite DGEBA/Fe( $\left(\mathrm{IO}_{3}\right)_{3}$ nanoparticles (a), compared to those of pure DGEBA (b) and $\mathrm{Fe}\left(\mathrm{IO}_{3}\right)_{3}$ nanoparticles (c). 


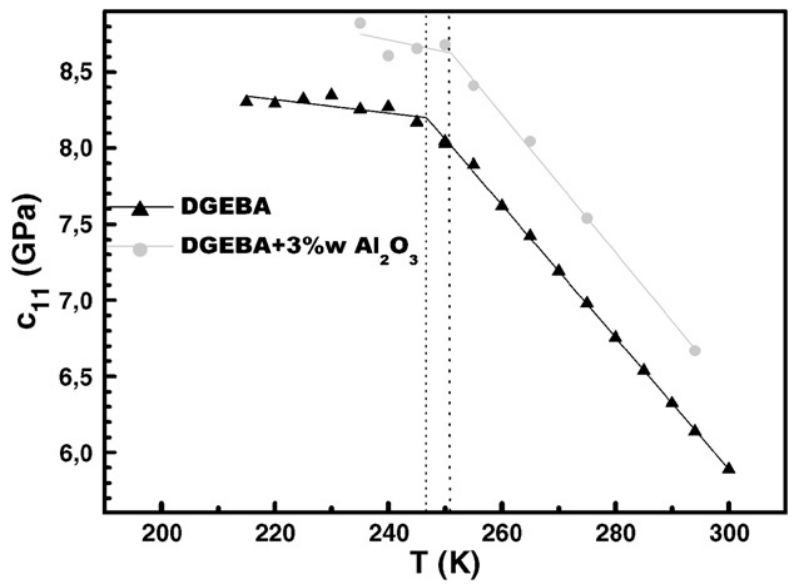

Fig. 6. Evolution of the elastic constant $c_{11}$ (Young's modulus) versus temperature for pure DGEBA (triangles) and nanocomposites (circles).

nanocrystals, the diffraction peaks present the same diffraction angles and intensities as the calculated spectrum.

In various iodate crystals, the four fundamental frequencies of the pyramidal iodate ion have been observed in Raman spectroscopy. In our case, the wavelength of the laser diode used for Raman spectroscopy is of $787 \mathrm{~nm}$. The power used is of $30 \mathrm{~mW}$. In the Raman spectra (Fig. 5) we can identified the vibrational modes $v_{1}$ (symmetrical stretching) at $791 \mathrm{~cm}^{-1}, v_{2}$ (symmetrical bending) at $396 \mathrm{~cm}^{-1}, v_{3}$ (asymmetrical stretching) at $823 \mathrm{~cm}^{-1}$ and $v_{4}$ (asymmetrical bending) at $329 \mathrm{~cm}^{-1}$.

These four fundamental vibrations, typical for iodate ion, have been previously identified for $\mathrm{Fe}\left(\mathrm{IO}_{3}\right)_{3}$ at very close wave numbers, respectively at $779 \mathrm{~cm}^{-1}, 395 \mathrm{~cm}^{-1}, 826 \mathrm{~cm}^{-1}$ and $330 \mathrm{~cm}^{-1}$ [17]. In addition, another vibration can be observed at $448 \mathrm{~cm}^{-1}$. In Ref. [17] this peak is identified at $451 \mathrm{~cm}^{-1}$ as $\mathrm{Fe}-\mathrm{O}$ vibrations.

The Raman spectrum of DGEBA (Fig. 5) is typical of an epoxy resin and has been extensively studied in a previous work [18]. Concerning the nanocomposite, no influence of the nanoparticles on the matrix can be seen on the Micro-Raman spectrum (Fig. 5). Therefore, the chemical interactions between the nanoparticles and the oligomer matrix seem very weak. However this conclusion must be moderate because of the noise coming from the high elastic diffusion coming from clusters, as it can be seen on the different spectra.

Similar measurements have been performed with $\mathrm{Al}_{2} \mathrm{O}_{3}$ nanoparticles and nanocomposite based on $\mathrm{Al}_{2} \mathrm{O}_{3}$ nanoparticles. No influence on the nanoparticles and on the matrix properties has been pointed out. The Raman spectrum of the nanocomposite results from the sum of both nanoparticles and DGEBA spectra.

\subsection{Mechanical properties of the nanocomposite}

Brillouin scattering measurements were performed in order to determine the elastic constants of the nanocomposite material. The laser light scattered by the sample was analysed perpendicularly to the incident beam by a 5-pass Fabry-Pérot interferometer. The velocity of the acoustic phonons was deter- mined taking into account the scattering geometry through the relation:

$v_{i}=\frac{f_{i} \lambda_{0}}{\sqrt{2}}$

where $v_{i}$ is the longitudinal or transversal sound velocity, $f_{i}$ is the frequency of the longitudinal or transversal phonon and $\lambda_{0}$ is the Ar laser wavelength $(514.5 \mathrm{~nm})$. One have to notice that, with this geometry, the measured frequency does not depend on the refractive index [19]. Starting from the sound velocity, we can determine the elastic constants through the relation (2). For an isotropic material, which is the case here:

$c_{i i}=\rho v_{i}^{2}$

$c_{i i}$ are the elastic constants in Voigt notation, $v_{i}$ the sound velocity and $\rho$ the density of the material. To study the influence of temperature, we use a vacuum cryostat, under nitrogen flow. The experiment's temperature ranges from $100 \mathrm{~K}$ to $400 \mathrm{~K}$.

First samples were prepared with dispersion and ball milling for $1 \mathrm{~h}$ with $3 \%$ weight alumina nanoparticles with an average size of 2-4 nm (Sigma-Aldrich).

The temperature evolution of the elastic constant $c_{11}$, related to the longitudinal mode, has been fitted by an empirical equation (3). As long as the material remains in the same phase, the elastic constants vary linearly versus temperature. Thus, the glass transition will be identified as a change of slope, which allows determining the glass transition temperature $T_{\mathrm{g}}$ :

$c_{11}=a-b T-c\left|T-T_{\mathrm{g}}\right|$

The first results on DGEBA with alumina nanoparticles shows an increment of $c_{11}$ (Fig. 6), with a shift of the glass transition temperature $T_{\mathrm{g}}$ from $247 \mathrm{~K}$ to $251 \mathrm{~K}$. As the signal intensity decreases at low temperature, measurements below $235 \mathrm{~K}$ with the nanocomposites are not taken into account. The interaction zone hypothesis is often used to explain the changes in mechanical properties [20] and glass transition temperature [21] that occur with the addition of nanoparticles in the matrix.

At the present time, the mixture of DGEBA and iron iodate nanoparticles exhibits a strong Rayleigh scattering. This scattering is too large for our high sensitive photomultiplier and then prevents Brillouin scattering measurement. Indeed, even if most of the clusters are destroyed after the dispersion process, the remaining clusters induce Mie scattering. Up to now, our ball milling process is not efficient enough to provide transparent samples for Brillouin scattering. Several ways are currently explored in order to determine better parameters for the specific case of iron iodate nanoparticles dispersion. We assume that the size, the morphology and the chemical interactions within the clusters are responsible for the different behaviours between the $\mathrm{Al}_{2} \mathrm{O}_{3}$ and $\mathrm{Fe}\left(\mathrm{IO}_{3}\right)_{3}$ nanoparticles.

\section{Conclusion}

$\mathrm{Fe}\left(\mathrm{IO}_{3}\right)_{3}$ nanoparticles were obtained by a co-precipitation method, which leads to two kinds of nanoparticles shapes, ball 
and needle. Their size of 20-30 nm in diameter was measured and confirmed by several methods, such as SEM, TEM and AFM. The nanopowders are of pure $\mathrm{P}_{3}$ phase as confirmed by $\mathrm{X}$-ray diffraction. Thanks to their crystallographic structure, these nanoparticles are supposed to present piezoelectrical and possible ferroelectrical properties.

$\mathrm{Al}_{2} \mathrm{O}_{3}$ and $\mathrm{Fe}\left(\mathrm{IO}_{3}\right)_{3}$ nanoparticles were totally or partially dispersed in an oligomer matrix, before future addition to the hardener to realize a polymer. In this study we have shown by Raman spectroscopy that $\mathrm{Al}_{2} \mathrm{O}_{3}$ and $\mathrm{Fe}\left(\mathrm{IO}_{3}\right)_{3}$ nanoparticles do not present clear chemical interaction with the only oligomer. This would probably not be the case with the polymer matrix.

As far as mechanical properties are concerned, this study shows by Brillouin spectroscopy that even a low content of the matrix in nanoparticles (3\% in weight) leads to an increase of the elastic constants of the material, in particular the Young's modulus $c_{11}$, and to a clear shift of the glass transition temperature from 247 to $251 \mathrm{~K}$.

Work is in progress to improve the dispersion parameters and to eliminate $\mathrm{Fe}\left(\mathrm{IO}_{3}\right)_{3}$ clusters in the nanocomposite, before studying properties of the cured polymer mixed with the polar nanocrystals.

\section{References}

[1] R.E. Sykora, D.M. Wells, T.E. Albrecht-Schmitt, J. Solid State Chem. 166 (2002) 7.

[2] R.E. Sykora, D.M. Wells, T.E. Albrecht-Schmitt, Inorg. Chem. 41 (2002) 2304.

[3] K.M. Ok, P.S. Halasyamani, Angew. Chem. Int. 43 (2004) 41.
[4] R.E. Sykora, T.E. Albrecht-Schmitt, Inorg. Chem. 42 (2003) 7.

[5] T.E. Albrecht-Schmitt, P.M. Almond, R.E. Sykora, Inorg. Chem. 42 (12) (2003) 3788 .

[6] T.C. Shehee, R.E. Sykora, K.M. Ok, P.S. Halasyamani, T.E. AlbrechtSchmitt, Inorg. Chem. 42 (2) (2003) 457.

[7] R.E. Sykora, K.M. Ok, P.S. Halasyamani, T.E. Albrecht-Schmitt, J. Am. Chem. Soc. 124 (2002) 9.

[8] K.M. Ok, P.S. Halasyamani, Inorg. Chem. 44 (2005) 7.

[9] X. Chen, H. Xue, X. Chang, H. Zang, W. Xiao, J. Alloys Compd. 398 (2005) 173.

[10] X. Chen, H. Xue, X. Chang, H. Zang, W. Xiao, J. Alloys Compd. 396 (2005) 255.

[11] P. Douglas, A.L. Hector, W. Levason, M.E. Light, M.L. Matthews, M. Webster, Z. Anorg. Allg. Chem. 630 (2004) 3.

[12] A.L. Hector, S.J. Henderson, W. Levason, M. Webster, Z. Anorg. Allg. Chem. 628 (2002) 1

[13] P. Jolivet, C. Froidefond, A. Pottier, C. Chanéac, S. Cassaignon, E. Tronc, P. Euzen, J. Mater. Chem. 14 (2004).

[14] L. Vayssières, C. Chanéac, E. Tronc, J.P. Jolivet, J. Colloid Interface Sci. 205 (1998) 8.

[15] A. Von Endrédy, Z. Anorg. Allg. Chem. 217 (1) (1934) 53.

[16] C. Galez, Y. Mugnier, J. Bouillot, Y. Lambert, R. Le Dantec, J. Alloys Compd. 416 (1-2) (2006) 261.

[17] M. Ristic, S. Music, M. Ivanda, J. Mol. Struct. 480-481 (1999) 637.

[18] A. Boukenter, E. Duval, H.M. Rosenberg, J. Phys. C 21 (1988) 541.

[19] J.K. Krüger, in: H. Bässler (Ed.), Optical Techniques to Characterize Polymers Systems, Elsevier, Amsterdam, 1989.

[20] J.K. Krüger, U. Müller, R. Bactavatchalou, J. Mainka, C. Gilow, W. Possart, A. Tschöpe, P. Alnot, D. Rouxel, R. Sanctuary, B. Wetzel, J. Phys. IV France 129 (2005) 45.

[21] J.K. Krüger, R. Holtwick, A. le Coutre, J. Baller, Nanostruct. Mater. 12 (1) (1999) 519. 